\title{
Mucin histochemistry of the columnar epithelium of the oesophagus (Barrett's oesophagus): a prospective biopsy study
}

\author{
MICHEL PEUCHMAUR, FRANÇOIS POTET, DENIS GOLDFAIN \\ From the Department of Pathology, Hospital Beaujon, F 92118 Clichy Cedex and Inserm Unite 239
}

SUMMARY Columnar epithelium-lined oesophagus (CELO) is an acquired disorder associated with a high incidence of cancer. CELO consists of three histological types of epithelium: gastricfundic, junctional, and specialised columnar, the last resembling intestinal metaplasia of the stomach. In a previous study of CELO an incompletely differentiated variant of intestinal metaplasia secreting sulphomucins (type II B) was found. This was shown to be associated with well differentiated adenocarcinoma, as in the stomach. The purpose of this paper has been to define by histochemistry the mucin profile of CELO in 17 patients and to compare it with the mucin profile of the gastroesophageal junction in 27 patients without CELO. In CELO a specialised columnar epithelium was always found and type II B intestinal metaplasia (with sulphomucins) showed the highest incidence (53\%). In normal subjects, this type of intestinal metaplasia was found in only three of 27 cases. Type II B intestinal metaplasia has often been considered as a precancerous lesion or as an equivalent of dysplasia; consequently, its high incidence in our study on CELO raises the question of whether this lesion should be considered a high risk condition for adenocarcinoma of the lower oesophagus.

Columnar epithelium-lined oesophagus (CELO), or Barrett's oesophagus, is a disorder in which the lower oesophagus is lined by columnar instead of squamous epithelium. CELO is usually an acquired condition complicating prolonged reflux oesophagitis ${ }^{1}$ and is of considerable interest because there have been several reports of a high incidence of adenocarcinoma arising in CELO, mostly in surgical specimens ${ }^{23}$ and in some biopsy material. ${ }^{45}$ Naef $\mathrm{et}^{\mathrm{al}} \mathrm{l}^{4}$ established the premalignant character of CELO, finding a $10 \%$ incidence of adenocarcinomas in a series of 140 biopsy samples. In another biopsy series, Savary et al $^{5}$ found an even higher incidence $(15.7 \%)$ of malignant changes in CELO.

Paull et $a^{6}$ showed that CELO consisted of three histological types of epithelium: gastric-fundic, junctional, and specialised columnar. The last is a very distinctive epithelium, ${ }^{7}$ resembling intestinal metaplasia of the stomach. $\mathrm{Jass}^{8}$ showed that mucin histochemistry was helpful in further classifying specialised columnar epithelium. They found an

Accepted for publication 6 February 1984 incompletely differentiated variant of intestinal metaplasia secreting sulphomucins (type II B) associated with well differentiated adenocarcinoma in CELO, as previously described in the stomach by other authors. $^{9+12}$

Using biopsy material we have attempted to define the mucin profile of CELO and of the normal gastroesophageal junction by means of a prospective histochemical study carried out over two and a half years.

\section{Material and methods}

Forty four patients with symptoms of reflux oesophagitis were included in this study: 30 men and 14 women (mean age 52 years). Endoscopic examination and biopsy were performed on all these patients from January 1981 to June 1983. CELO was diagnosed in 17 patients (15 men and two women, mean age 51.5 years) on the basis of endoscopic changes and histological evidence of columnar lined epithelium. The other 27 patients (15 men and 12 women, mean age 52.3 years) did not show CELO by the above criteria. The number of biopsy 
samples taken from each patient ranged from two to 13 (mean 4.76) in the 17 patients with CELO and from two to six (mean 3.55) in those without CELO.

All the samples were fixed in $3.6 \%$ neutral buffered formalin (modified Millonig's phosphate buffer) for $\mathbf{4 8} \mathrm{h}$ and paraffin embedded. Serial sections, $4 \mu \mathrm{m}$ thick, were cut from each sample and stained with the following: haematoxylin and eosin; alcian blue and periodic acid Schiff, $\mathrm{pH} 2 \cdot 5$, to differentiate acid from neutral mucins; and high iron diamine and alcian blue, $\mathrm{pH} 2 \cdot 5$, to differentiate sulphomucins from sialomucins. ${ }^{13} 14$

\section{Results}

The histological and histochemical study of CELO showed heterogeneity. The incidence of the three histological types of epithelium of CELO as described by Paull et al $l^{6}$ is shown in Table 1 . The two most common types were the junctional type (16) and the specialised columnar epithelium type (17). No dysplasia was found.

The histochemical reactions used for identifying epithelial mucins are shown in Table 2: neutral mucins stain with periodic acid Schiff, acid mucins are stained mainly with alcian blue, and sulphomucins are stained with high iron diamine. In CELO, both gastric fundic and junctional

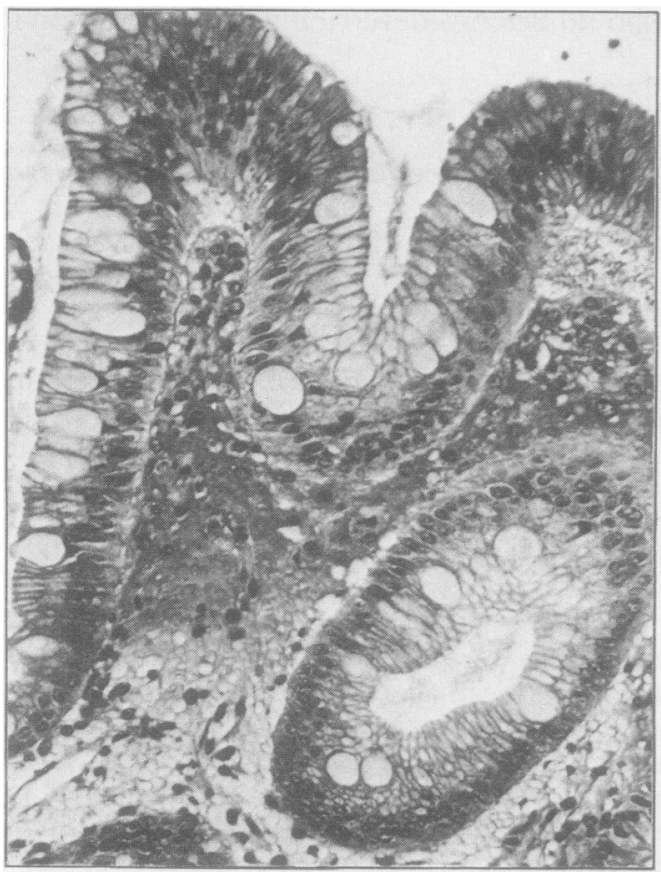

Fig. 1 Incomplete intestinal metaplasia with goblet cells and intervening columnar cells. Haematoxylin and eosin. $\times 225$
Table 1 Incidence of the three histological types of epithelium in 17 cases of CELO

\begin{tabular}{lc}
\hline Histological type & No of patients* \\
\hline Gastric-fundic & 4 \\
Junctional & 16 \\
Specialised & 17 \\
\hline
\end{tabular}

* Overall total is greater than 17 patients because more than one type of epithelium occurred in some patients.

Table 2 Histochemical techniques used to characterise gastrointestinal mucins

\begin{tabular}{lll}
\hline & $A B-P A S$ & $H I D-A B$ \\
\hline $\begin{array}{l}\text { Neutral mucins } \\
\text { Sialomucins }\end{array}$ & Magenta & O \\
N-Acetyl & Purple-blue & Blue \\
O-Acetyl & Blue & Blue \\
Sulphomucins & Blue & Brown-black \\
\hline
\end{tabular}

$\mathrm{O}=$ negative staining

PAS = periodic acid Schiff,

$\mathbf{A B}=$ alcian blue

HID $=$ high iron diamine.

Table 3 Incidence of intestinal metaplasia subtypes in CELO

\begin{tabular}{|c|c|}
\hline Intestinal metaplasia subtypes & No of patients \\
\hline $\begin{array}{l}\text { II } \\
\text { IIIA }\end{array}$ & $\left.\begin{array}{l}3 \\
2 \\
3\end{array}\right\}$ \\
\hline $\begin{array}{l}\text { IIA-IIB } \\
\text { IIB } \\
\text { Total }\end{array}$ & $\left.\begin{array}{r}3 \\
6 \\
17\end{array}\right\}$ \\
\hline
\end{tabular}

*Total of CELO with sulphomucins.

epithelium showed only neutral mucin secretion. Specialised columnar epithelium is characterised by intestinal metaplasia with goblet cells secreting acid mucins and intervening columnar cells (Fig. 1). Complete intestinal metaplasia type $I$ is defined by the presence of columnar cells resembling normal enterocytes without mucus secretion. Incomplete intestinal metaplasia type II $\mathbf{A}$ is defined by the presence of columnar cells secreting neutral mucins or traces of sialomucins and type II B by the presence of columnar cells secreting sulphomucins (Fig. 2). Type II B showed the highest incidence and was fairly extensive but often focal and associated with other types of intestinal metaplasia. Table 3 shows the incidence of intestinal metaplasia subtypes I, II A, and II B.* Forms of transition in terms of morphology and mucin profiles between these three well recognisable variants were also noted (I-II A, I-II A-II B, II A-II B). Nine of 17 cases of CELO (about half) showed the presence of sulphomucins. In 21 of 27 patients without CELO, biopsy samples

*Recently Filipe et al's proposed the term type II and type III intestinal metaplasia instead of type II A and type II B respectively. 


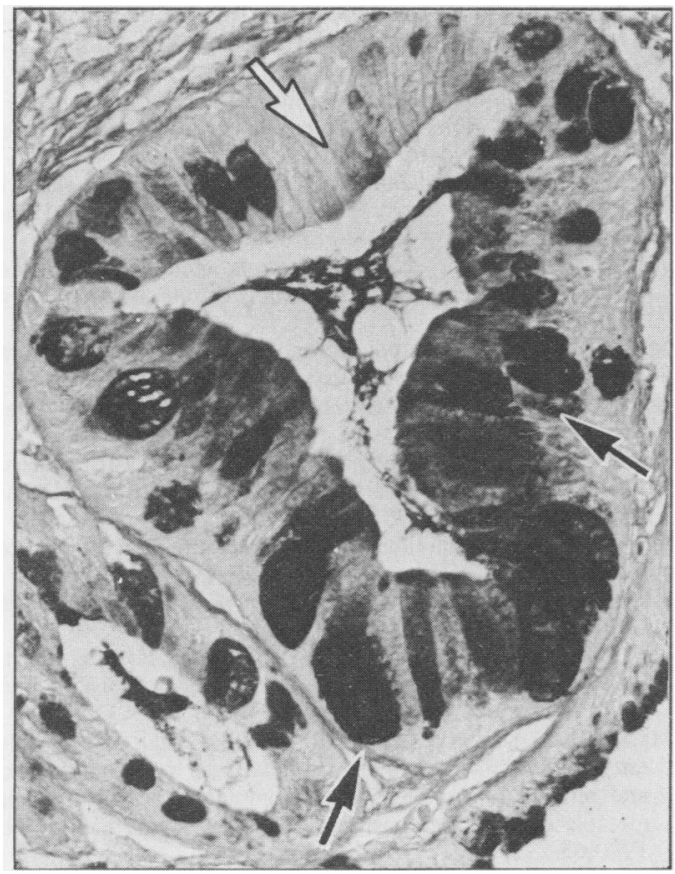

Fig. 2 Incomplete intestinal metaplasia type II B with goblet and columnar cells secreting sulphomucins (black arrows) and sialomucins (white arrow). High iron diamine and alcian blue combined reaction. $\times 325$

from the gastroesophageal junction showed a periodic acid Schiff positive reaction in mucus secreting cells lining the surface epithelium and cardiac glands. Nevertheless, in the six remaining patients without CELO, the histochemical reactions showed intestinal metaplasia either with $(3 / 6)$ or without (3/6) secretion of sulphomucins. Minimal amounts of sulphomucins may occasionally be found in cardiac glands of normal gastroesophageal junction and should not be confused with the positive staining for sulphomucins obtained in intestinal metaplasia.

\section{Discussion}

Histochemical study of intestinal metaplasia has previously been carried out in the stomach..$^{9-12}$ Gastric intestinal metaplasia is characterised by globlet cells and columnar cells. The complete type of intestinal metaplasia (I) consists of mature absorptive and goblet cells; the incomplete type (IIA and IIB) consists of few or absent absorptive cells, goblet cells, and columnar "intermediate" cells in various stages of differentiation." These columnar "intermediate" cells can secrete neutral mucins, sialo- or sulphomucins. Type II B intestinal metaplasia (secreting sulphomucins) is often associated with well differentiated adenocarcinoma of the stomach..$^{11} 1216$ Recently, a mucin histochemical study of CELO suggested a similar histogenetic relation between type II B intestinal metaplasia and well differentiated adenocarcinoma of the oesophagus. ${ }^{8}$

Our present prospective study emphasises the following aspects of CELO.

Nine of 17 patients with CELO showed type II B intestinal metaplasia (53\%); this is in contrast with the conspicuous absence of sulphomucins in normal columnar epithelium of the gastroesophageal junction. Our results are comparable with those of two recent histochemical studies of intestinal metaplasia, one in CELO and the other in gastric biopsy specimens. In a series of 10 cases of CELO (nine biopsy and one surgical specimens), $\mathrm{Jass}^{8}$ found type IIB intestinal metaplasia in three of 10 cases (focal only) and IIA intestinal metaplasia in five of 10 cases (usually extensive). In a prospective study of intestinal metaplasia in 1460 gastric biopsy specimens, Filipe $e$ al $^{15}$ showed a $8.7 \%$ incidence of type IIB intestinal metaplasia in 272 specimens with intestinal metaplasia. Our results as well as those of the above two studies show a higher incidence of type IIB intestinal metaplasia in CELO. Although the number of cases is small in our study, it would appear that the incidence of type IIB intestinal metaplasia is very high in CELO. With regard to a possible precancerous connotation of type II B intestinal metaplasia, our findings are consistent with the hypothesis that patients with CELO represent a very high risk cancer group.

Thompson et al ${ }^{17}$ suggested that Barrett's oesophagus (CELO) could be important as a precursor of adenocarcinoma arising in the region of the lower oesophagus and gastroesophageal junction. In six biopsy specimens taken from the gastroesophageal junction of patients with reflux oesophagitis but without CELO, intestinal metaplasia of either type II A (three) or type II B (three) was found. These results suggcst that the same type of intestinal metaplasia could be present in patients with reflux oesophagitis, whether intestinal metaplasia is found above (that is, CELO) or at the level of an endoscopically normal gastroesophageal junction. Consequently, the pathogenesis of adenocarcinoma of the lower oesophagus and of adenocarcinomas arising in the gastric cardia could be identical.

It would be of considerable interest to obtain a complete follow up of patients whose biopsy specimens contained II B intestinal metaplasia in order to see if type II B intestinal metaplasia could truly serve as a useful marker in reflux oesophagitis. Dysplasia has rarely been found in CELO. Among the biopsy specimens of 23 cases of CELO not associ- 
ated with adenocarcinoma, Skinner $e^{2} a^{3}$ noted "low grade" (mild) dysplasia in only two cases. On the other hand, "high grade" or severe dysplasia often occurs adjacent to adenocarcinoma arising in CELO. ${ }^{3418}$ When found in CELO, high grade or severe dysplasia is probably a good marker of malignant risk. Because of the low incidence of mild dysplasia in CELO, type IIB intestinal metaplasia could be a useful marker and regarded as a form of mild dysplasia in the screening for adenocarcinoma in CELO.

We are grateful to Mrs Paris and Miss Perennec for their excellent technical assistance and we gratefully acknowledge the assistance of Dr WV Bogomoletz in the preparation of this manuscript. We also thank Mr Wolfelsperger for the microphotographs.

\section{References}

' Bremmer CG, Lynch VS, Ellis FA. Barrett's esophagus: congenital or acquired? An experimental study of eosophageal mucosal regeneration in the dog. Surgery 1970;68:209-16.

${ }^{2}$ Berenson MM, Riddell RH, Skinner DB, Freston JW. Malignant transformation of esophageal columnar epithelium. Cancer 1978;41:554-61.

${ }^{3}$ Skinner DB, Walther BC, Riddell RH, Schmidt H, Iascone C, Demeester TR. Barrett's esophagus. Comparison of benign and malignant cases. Ann Surg 1983;198:554-66.

4 Naef AP, Savary M, Ozzello L. Columnar-lined lower esophagus: an acquired lesion with malignant predisposition. Report on 140 cases of Barrett's esophagus with 12 adenocarcinomas. J Thorac Cardiovasc Surg 1975;70:826-35.

s Savary M, Guinard G. Problèmes de carcinogénèse sur le basoesophage. Acta Endoscop 1977;7:217-24.
- Paull A, Trier JS, Dalton MO, Camp RC, Loeb P, Goyal RK. The histologic spectrum of Barrett's esophagus. N Engl J Med 1976;295:476-80.

7 Trier JS. Morphology of the epithelium of the distal esophagus in patients with midesophageal peptic strictures. Gastroenterology 1970;58:444-61.

${ }^{8}$ Jass JR. Mucin histochemistry of the columnar epithelium of oesophagus. A retrospective study. J Clin Pathol 1981;34:866-70.

9 Jass JR, Filipe MI. A variant of intestinal metaplasia associated with gastric carcinoma: a histochemical study. Histopathology 1979;3:191-5.

10 Jass JR, Filipe MI. Sulphomucins and precancerous lesions of the human stomach. Histopathology 1980;4:271-9.

" Jass JR. Role of intestinal metaplasia in the histogenesis of gastric carcinoma. J Clin Pathol 1980;33:801-10.

12 Jass JR, Filipe MI. The mucine profils of normal gastric mucosa, intestinal metaplasia and its variants and gastric carcinoma. Histochem J 1981;13:931-9.

${ }^{13}$ Spicer SS. Diamine methods for differentiating mucosubstances histochemically. J Histochem Cytochem 1965;13:211-34.

14 Filipe MI, Lake BD. Histochemistry in pathology, Edinburgh: Churchill Livingstone, 1983:312.

${ }^{15}$ Filipe MI, Bogomoletz W, Dawson P, Fabiani B, Potet F. Intestinal metaplasia in the assessment of gastric cancer risk. A multicentric prospective study (Abstract). Gut 1983;24:974-5.

${ }^{16}$ Matsukura N, Suzuki K, Kawachi T, et al. Distribution of marker enzymes and mucin in intestinal metaplasia in human stomach and relation of complete and incomplete types of intestinal metaplasia to minute gastric carcinomas. J Natl Cancer Inst 1980;65:231-40.

${ }^{17}$ Thompson JJ, Zinsser KR, Enterline HT. Barrett's metaplasia and adenocarcinoma of the esophagus and gastroesophageal junction. Hum Pathol 1983;14:42-61.

${ }^{18}$ Haggitt RC, Tryzelaar J, Ellis FM, Colcher H. Adenocarcinoma complicating columnar epithelium-lined (Barrett's esophagus). Am J Clin Pathol 1978;70:1-5.

Requests for reprints to: Pr F Potet, Department of Pathology, Hospital Beaujon, F 92118 Clichy Cedex, France. 